\title{
Meningitis - what precaution is needed for central neuraxial blockade
}

Meningitis remains as an acknowledged iatrogenic complication following spinal and epidural anesthesia performed for surgical procedure with a relatively low incidence (less than 4.5 per $1,00,000)^{1}$. The infection is introduced during cerebral surgery, pneumoencephalography, placement of a ventriculoperitoneal shunt, epidural steroid injection, myelography or rarely by lumbar puncture. Patients undergoing urological procedures or women in active labour belong to a special group that is more prone to developing bacteremia.

Pertinent question is how prevalent is the apparent lack of familiarity with this rare but dreadful complication in the medical community. World wide only 60 cases have been identified with only 3 deaths $(5 \%)^{2}$. The death rate is considerably lower than that of the community acquired meningitis (3$29 \%)^{3,4}$.

The latency period from the offending procedure to the appearance of the symptom is 8 hours to 30 days. (mean 41.1 hour, median 2.5 hour) ${ }^{2}$. Patient usually develops the symptoms of acute meningitis like headache associated with vomiting, photophobia, fever, followed by altered mental status within 48 to 72 hours after spinal anesthesia ${ }^{2}$. Most of the patients belong to age group of 16 to 76 years (mean 45.7 year, median 44 year) with equal male and female distribution. The patient recovering from the acute phase of the disease sometimes left with neurological consequences like cranial nerve palsies, hemiparesis, quadriparesis and aphasia which is also in a low rate in comparison $33-50 \%$ of cases of community acquired meningitis ${ }^{5}$.

The mechanism of infection is not always clear and may be due to aseptic failure with direct introduction of bacteria in the sterile cerebro spinal fluid or presence of asymptomatic bacteremia during the lumbar puncture and contamination of subarachnoid space by microscopic bleeding caused by insertion of the contaminated needles. Interference of the skin sterilization and contamination of the lumbar puncture equipment or the anaesthetic agents are the possible sources of infection. Reuse of spinal needles are also responsible as they may contain fragments of skin and iodine. Manipulation of the uterus for retained placenta, use of blood patch for post dural puncture headache elevates the rate of infection. Other possible route of infection is droplet contamination by oropharyngeal secretions of the medical personnel.

Among the various organisms implicated in iatrogenic meningitis $83 \%$ is gram positive bacteria and $17 \%$ is gram negative bacteria. Among the gram positive organisms viridans group of Streptococci are the most prevalent group of organisms isolated in $60 \%$ cases followed by Staphylococcus (6\%). Recent reports indicate that sterptococcus. salivaris may be the most commonly associated organism followed by Streptococcus mitis and Streptococcus sanguis $^{2}$. Causative gram negative organism are Pseudomonas (15\%) and E.coli (2\%). Aspergillus spp. may gain access to the lumbar subarachnoid space during spinal anesthesia via haematogenous spread from an extra cranial site or extension from contagious extra cranial focus.

The Streptococci are indigenous to the oropharynx, female genital tract and the gastrointestinal tract. These organisms are typically of low virulence and when isolated from culture they are often dismissed as contaminants but once in spinal fluid they rapidly multiply causing a full blown purulent meningitis in 7-24 hours ${ }^{6}$. No deaths or major complications occurred as a consequence of streptococcal meningitis.

One hypothesis for the mechanism of infection relates "The sudden lowering of the CSF pressure with a breaking down of the blood brain barrier". Other hypothesis is that the spinal needle picks up the organism as it punctures the small vessels on its path toward the spinal canal and then directly deposits the organism into the $\mathrm{CSF}^{7}$.

The meningeal pathogen must sequentially colonize the host mucosal epithelium, invade the intravascular space, cross the blood brain barrier 
and survive in the CSF.The first two of these antibacterial obstacles involve IgA proteases, bacterial pilli, binding epitopes and molecular basis of complement evasion. The meningeal pathogen circumvents the first three obstacles in those cases where it is inoculated directly into the CSF. At the onset tumor nurotic factor and other host cytokines may be found in the CSF. There is strong experimental evidence that these inflammatory cytokines induce inflammation and break down the blood brain barrier. Other mechanisms allow entrance into the CSF of leucocytes which on break down emit toxic metabolites that can lead to vasogenic brain edema. There is a resulting loss of cerebrovascular autoregulation subjecting the brain to the risk of hyperperfusion or hypoperfusion.

The suspicion of meningitis should immediately trigger the collection of blood and CSF for microscopy, culture and analysis. Head Computed Tomography scan is advised before lumbar punctured to exclude signs of mass lesion and increased intracranial pressure.

Gram stain is of considerable value as it is positive for $42 \%$ cases. This rate is lower than the corresponding rate of $75 \%$ in non iatrogenic meningitis ${ }^{[2]}$. Blood culture is positive in $15 \%$ cases and $2.6 \%$ of it is Viridans group of Streptococci.

The CSF appears cloudy, sometimes fluid is described as having 'shut out'. The CSF characteristics are typical of bacterial meningitis. White cell count range from 1400 to 56000 with polymorphonuclear predominance. Protein content is high ranging from 45 to $1080 \mathrm{mg} / \mathrm{dl}$ and glucose level of 8 to $82 \mathrm{mg} / \mathrm{dl}^{[2]}$. Despite the CSF negative culture a bacterial cause for the patients condition cannot be excluded as most of the time LP is performed after starting antibiotic. The antibiotics might render the CSF gram stain and culture negative. DNA bacterial probes and rapid identification of the organism to species level are available. Their application in the clinical settings will provide a earlier detection and identify the possible break in sterile techniques.

Diagnosis of iatrogenic meningitis may be confused and delayed for conditions like viral meningitis, chemical meningitis from disinfectants and detergents and drug associated meningitis.
There may be a significant interval between establishing the diagnosis of meningitis and the initiating appropriate therapy. In these patient appropriate and adjunctive therapy given prior to lumbar puncture or before the patient is sent for CT. Delay in the initiation of therapy introduces the potential for increased mortality and morbidity. Targeted antimicrobial therapy is based on primitive pathogen identification by CSF gram stain, although the combination of vancomycin plus either ceftriaxone or cefotaxime is used.

A study by Van doern et al. ${ }^{8}$ found that only $44 \%$ of Viridans Streptococcus were highly susceptible to penicillin while $43 \%$ were intermediately resistant ( with minimal inhibitory concentration $1-2 \mu \mathrm{g} / \mathrm{ml}$ ) and

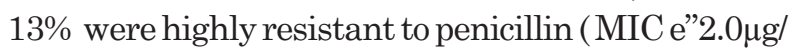
$\mathrm{ml}$ ). This emerging resistance indicates a concern for acceptable alternatives to penicillin include vancomycin, teicoplanin, imipenem and chloramphenicol ${ }^{8,9} .15-20 \%$ of Viridans Streptococci are resistant to ceftriaxone, with an MIC of $8.0 \mu \mathrm{g} /$ $\mathrm{ml}^{[2]}$. The IDSA (Infection Disease Society of America) guidelines recommend the adjunctive dexamethasone be continued for 2-4 days only if CSF gram stain reveals gram positive diplococci in blood or in CSF cultures are positive for S. pneumoniae ${ }^{12}$.

Guidelines for spinal anesthesia should underline the need to wear a surgical face mask with high bacterial filtering efficiency and thus reduce the bacterial contamination in proximity to the upper airway ${ }^{10,11}$. Any manipulation of the mask should be avoided. The facemask should be changed whenever it is touched and every 3 hours. Adequate aseptic precautions such as washing hands and skin cleaning with antiseptic solution, wearing sterile gloves, using properly sterilized needles before and during the procedure may reduce the incidence of this preventable and often fatal disease.

(Journal of BSA, 2009; 22(1): 1-3)

Prof. Md. Ruhul Amin Miah ${ }^{1}$, Dr. Shaheda Anwar ${ }^{1}$ Chairman, Department of Microbiology \& Immunology, Bangabandhu Sheikh Mujib Medical University, Shahbagh, Dhaka, ${ }^{2}$ M.Phil (Thesis Part), Department of Microbiology \& Immunology, Bangabandhu Sheikh Mujib Medical University, Shahbagh, Dhaka 


\section{Reference:}

1. Gorce P, Varlet C, Ouaknine B, Pourriat JL. [Meningitis after locoregional spinal anesthesia]. Ann Fr Anesth Reanim. 2000 May;19(5): French 375-381.

2. Yaniv LG, Potasman I. Iatrogenic meningitis: an increasing role for resistant viridans streptococci? Case report and review of the last 20 years. Scand J Infect Dis. 2000; 32(6): 693696.

3. Schlech III WF, Ward JI, Band JD, Hightower A, Fraser DW, Broome CV. Bacterial meningitis in the United States, 1978 through 1981. The National Bacterial Meningitis Surveillance Study. JAMA 1985; 253: 1749 54.

4. Wenger JD, Hightower AW, Facklam RR, Gaventa S, Broome CV, and the Bacterial Meningitis Study Group. Bacterial meningitis in the United States, 1986: report of a Multistate surveillance study. J Infect Dis 1990; 162: 1316 - 23.

5. Scheld WM. Bacterial meningitis, brain abscess, and other suppurative intracranial infections. In: Fauci AS, Braunwal ,E, Isselbacher KJ, Wilson JD, Martin JB, Kasper DL, Hauser SL, Longer DL, editors. Harrison's principles of Internal medicine. 14th ed. New York: McGraw-Hill, 1998; 2: 2419 - 34.
6. Estelle Traurig Baer. Iatrogenic meningitis : The Casefor Face Masks. Department of Medicine, Kaiseri/ Permanente Medical Center, Richmond, California.

7. Baumann DP, Koch LC. Streptococcal meningitis following diagnostic lumbar puncture. Ann Intern Med 1952; 36: 1090-2.

8. Van Doern G, Ferraro MJ, Brueggemann AB, Ruoff KL. Emergence of high rates of antimicrobial resistance among viridans group streptococci in the United States. Antimicrob Agents Chemother 1996; 40: 891 - 4.

9. Tunkel AR, Scheld WM. Acute meningitis. In: Mandell GL, Bennett JE, Dolin R, editors. Mandell, Douglas and Bennett's principles and practice of infectious diseases. 4th ed. New York: Churchill Livingstone, 1995; 1: 831 - 65.

10. Romney MG. Surgical face masks in the operating theatre: re-examining the evidence. J Hosp Infect 2001; 47: 251-256.

11. Philips BJ, Fergusson S, Armstrong P, Anderson FM, Wildsmith JA. Surgical face masks are effective in reducing bacterial contamination caused by dispersal from the upper airway. Br J Anaesth 1992; 69: 407-408.

12. Estelle Traurig Baer. Post Dural Puncture Bacterial Meningitis. Anesthesiology 2006; 105: 381-93. 